\title{
FXAT SCREEN
}

\section{JASON S. JOHNSON}

University of Calgary

JOSHUA TARON

University of Calgary
MATTHEW PARKER

University of Calgary

LOGAN ARMSTRONG

University of Calgary
CHRISTINA JAMES

University of Calgary
The FXAT Screen seeks to reclaim the presence of architecture and its imagery in the public realm. CNC milled opaque plywood panels produce a thickened surface revealing the material stratification within the planar surfaces. In direct contrast to the hyper smooth and streamlined aesthetic of contemporary media devices, the FXAT Screen wraps an artificial topography around an exaggerated cantilevered form that addresses both the pedestrian corridor of the urban core and the main venues for the RAIC Architecture Festival. A gradient of openings migrates across the form toward the street, concluding with a $14 \times 7$ foot rear projection screen showing the work of 15 emerging Canadian architecture firms in the RAIC's Future Voice: Situating Architecture Exhibition.

FXAT Screen is the result of a three-week design/build process and tight budget constraints. These design constraints led to a process that deployed rapid single pass milling techniques and soft tolerances in the pursuit of an urban communication object that is equal parts finely tuned (macro-form) and loosely articulated (micro-topology). FXAT Screen glows through the night communicating the collected architectural future on its flat projection

FXAT Screen was supported by a grant from the Social Sciences and Humanities Research Council and local sponsors. The exhibit was curated by Marc Boutin. 


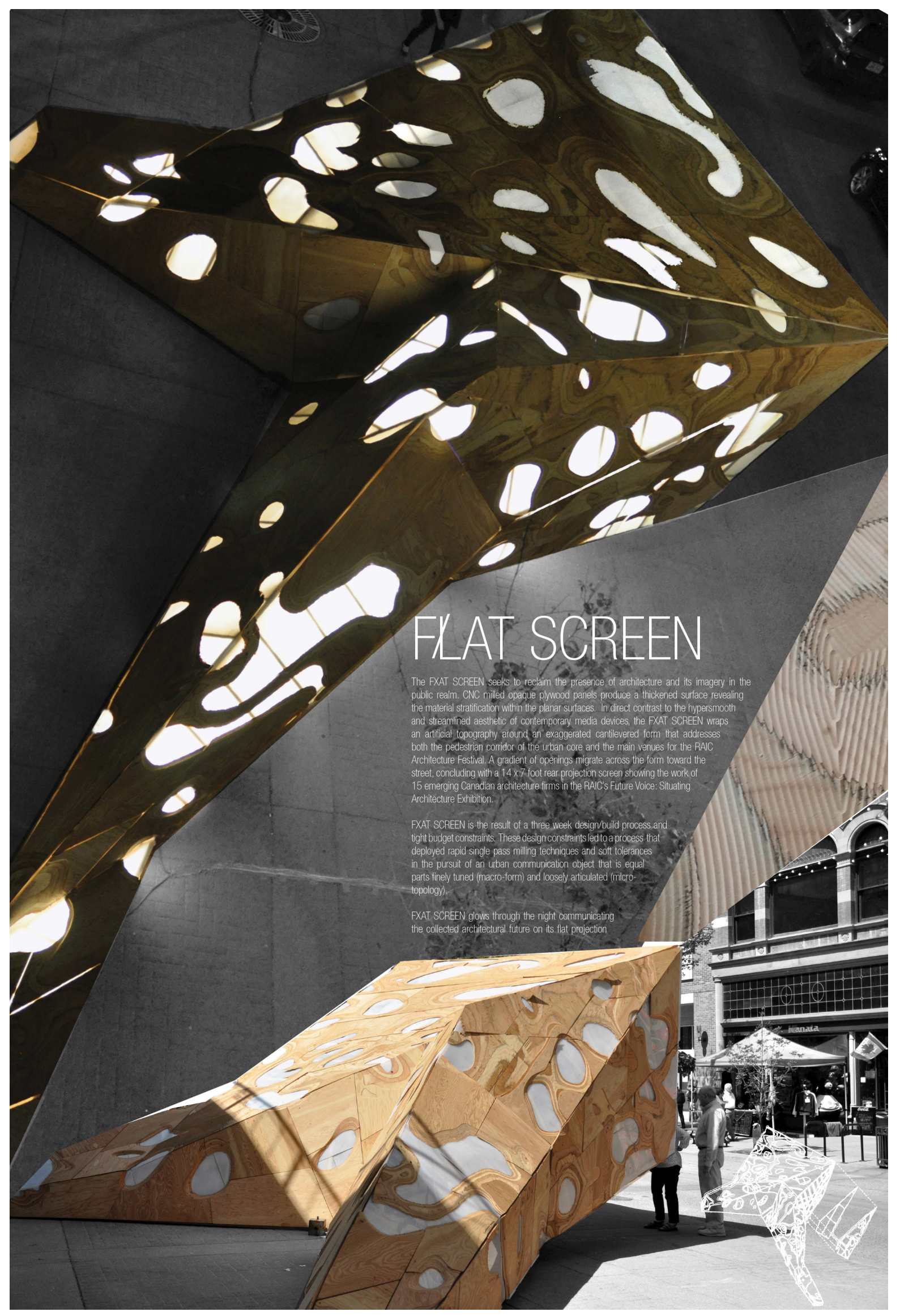

